\title{
A CONTROLADORIA APLICADA NA GESTÃO DE ESTOQUE DENTRO DAS INDÚSTRIAS
}

\section{ARTIGO ORIGINAL}

OLIVEIRA, Fabiane Félix de ${ }^{1}$, SILVA, Felipe de Oliveira ${ }^{2}$, BARDALES, Ketty Tavares ${ }^{3}$, ROBERTO, José Carlos Alves ${ }^{4}$, SERRA, Meg Rocha da Cunha ${ }^{5}$, LOPES, Nelânia Ferreira ${ }^{6}$

OLIVEIRA, Fabiane Félix de. Et al. A controladoria aplicada na gestão de estoque dentro das indústrias. Revista Científica Multidisciplinar Núcleo do Conhecimento. Ano. 06, Ed. 11, Vol. 02, pp. 83-102. Novembro 2021. ISSN: 24480959, Link de acesso:

https://www.nucleodoconhecimento.com.br/contabilidade/controladoria-aplicada, DOI: 10.32749/nucleodoconhecimento.com.br/contabilidade/controladoria-aplicada

\section{RESUMO}

O presente trabalho buscou apresentar a importância da controladoria no processo de gestão de estoque industrial e no auxílio aos gestores na tomada de decisão, através de pesquisa exploratória e revisão bibliográfica, buscando, desta forma, explicar a relação das funções de controladoria e o funcionamento desta, dentro da estrutura organizacional de estoque nas indústrias. Para alcançar o tema proposto nesta pesquisa, surgiu o seguinte questionamento: De que maneira a controladoria direcionada à gestão de estoque pode auxiliar na continuidade do negócio? Tem como objetivo geral analisar como a controladoria direcionada à gestão de estoque

\footnotetext{
${ }^{1}$ Estudante.

${ }^{2}$ Graduando do curso de contabilidade.

${ }^{3}$ Graduando do curso de contabilidade.

${ }^{4}$ Orientador. Mestre em Engenharia de produção. Especialista Logística empresarial. Graduado em Administração com Ênfase em Marketing.

${ }^{5}$ Orientadora. Mestra em Engenharia de Processos Industriais pela UFPA, especialista em Controladoria e Auditoria Contábil pelo Ciesa (2020), Graduada em Ciências Contábeis pelo Centro Universitário do Norte (2010). Graduada em Ciências Econômicas pelo Centro Universitário do Norte (2006).

${ }^{6}$ Orientadora. Especialista em Auditoria Contábil, Financeira e Tributaria e Graduada em Ciências Contábeis.
}

RC: 100626

Disponível em:

https://www.nucleodoconhecimento.com.br/contabilidade/controladoria-aplicada 
pode gerar informações adequadas para o processo decisório, auxiliando na continuidade da organização. Para isto, foram realizadas pesquisas de fundamentação teórica sobre controladoria, gestão, métodos de estoque, dentre os demais temas apresentados, bem como seus conceitos e definições de autores da área. Por fim, concluiu-se, através das informações apresentadas, que a controladoria pode auxiliar no processo da gestão de estoques a de tomada de decisão

Palavras-chaves: Controladoria, Processo de Gestão, Gestores, Ferramentas, Controle de estoque.

\section{INTRODUÇÃO}

As organizações estão em um ambiente em constante mudança, por este motivo para se manterem no mercado empresarial, de forma positiva, buscam aprimorar as informações na gestão. Esta área, por sua vez, é um dos suportes responsáveis por auxiliar o processo de tomada de decisão da empresa, a fim de apoiar os gestores dentro deste contexto (BREZAN e SILVA, 2012).

Para Padoveze (2009), o papel da controladoria é apoiar todo o processo de controle do negócio por meio de um sistema de informação, sendo responsável por garantir a eficiência da empresa, controlando os trabalhos executados e os resultados de seu plano. O sistema de informações de controle, é agregado ao sistema operacional e, a medição econômica da operação, é utilizada como um atributo para planejar, controlar e observar os resultados.

Segundam Dias (2015), toda empresa precisa de estoque, pois este é um amortecedor entre as várias etapas da produção até a venda final do produto. Contribuindo para essa afirmação, Ribeiro (2013), explica que, uma vez que muitas empresas compram mercadorias em datas e preços diferentes, com a finalidade de determinar o custo das mercadorias em estoque, os métodos de PEPS, UEPS e Custo Médio devem ser utilizados. 
Devido à variedade e a complexidade do assunto em questão, o estudo abordará o sistema de informação contábil-gerencial, destacando a gestão de estoques nas indústrias através de ferramentas da controladoria para tomada de decisões gerenciais.

Neste contexto, surge a seguinte problemática: De que maneira a controladoria direcionada à gestão de estoque pode auxiliar na continuidade do negócio? Tem como objetivo geral analisar como a controladoria direcionada à gestão de estoque pode gerar informações adequadas para o processo decisório, auxiliando na continuidade da organização

Portanto, inicialmente apresenta-se a introdução, seguido da revisão da literatura, com destaque a contextualização da controladoria e do estoque, apresentando-se as principais características e estudos correlatos sobre a estrutura organizacional da controladoria aplicada à gestão de estoque de uma indústria. $\mathrm{Na}$ terceira seção contemplam-se os procedimentos metodológicos da pesquisa e, na última seção, as considerações finais do estudo.

\section{FUNDAMENTAÇÃO TEÓRICA}

De acordo com Gil (2010), a fundamentação teórica consiste em todo o andamento das informações coletadas para apresentar características e métodos que serão abordados no decorrer do trabalho, sendo contextualizada da literatura, artigos e livros, proporcionando um avanço dos fundamentos teóricos. No decorrer deste tópico, visamos explicar a relação de controladoria dentro da gestão de estoque de uma indústria, buscando, nesse sentido, garantir que as informações adequadas sejam direcionadas aos gestores, já que estas são fundamentais para o aperfeiçoamento do processo decisório dentro da organização. 


\subsection{CONCEITOS DE CONTROLADORIA}

$\mathrm{Na}$ visão de Padoveze (2012), a controladoria é como uma ciência contábil crescente, que possibilita ao profissional a liberdade de implantar todas as suas ferramentas no desenvolvimento empresa, ou seja, realizar o uso da análise das circunstâncias estudadas pela contabilidade em relação à economia. Dessa maneira, fica claro a visão de que a controladoria e a contabilidade estão correlatas.

Para Rocha (2018), a controladoria e a contabilidade estão inter-relacionadas, sendo assim, dentre as outras ciências, são as que possuem relação mais próxima e centrada. Constata-se que esta é responsável por manter a exatidão dos registros contábeis e a comprovação de informações, compilando dados relevantes e reportando à administração. Nesse sentido, se pode considerar que o profissional da controladoria, o Controller, exerce sua influência e garante uma contribuição benéfica para a eficácia da gestão.

É notado por Bruni e Gomes (2010), que a controladoria é a junção de outras ciências e, tem como principal, a contabilidade, visando uma melhor gestão de forma a promover a eficiente relação interpessoal entre a empresa e seus processos de atividades.

Faz-se necessário identificar esse profissional, pois ele se torna o principal responsável no processo decisivo das indústrias, tendo como missão planejar e implantar os métodos conforme a exigência de mercado. Como bem assegura Müler e Beuren (2010), as empresas buscam que o profissional desta área tenha conhecimento e visão ampla em relação ao futuro da contabilidade gerencial e suas ferramentas, gerando informações e desenvolvendo atividades que amparem a diretoria nos processos decisivos da empresa.

Para Heichsen et al. (2014), mencionar que o responsável pela área de controladoria tem como objetivo influenciar o gestor a partir de uma opinião independente. Para o uso desta concepção, a controladoria precisa comunicar a visão divergente e 
defendê-la, o que acarreta a habilidade de convencer a outra parte com argumentos concretos.

Portanto para Bruni e Gomes (2010), a controladoria busca repentinamente fazer o papel de gestão em um modelo de visão empresarial, onde é possível ter uma visão da empresa por vários ângulos a fim de determinar a tomada de decisão.

\subsection{CONCEITOS DE ESTOQUES}

Pode-se dizer que o estoque deve ter o comprometimento de vários setores da empresa, pois, com isso, há eficiência positiva no atendimento aos clientes. (DIAS, 2010).

Para Ching (2010), o objetivo do estoque é estabelecer um controle entre o que comprar e qual momento a fim de verificar a relação de custos existentes na compra de mercadorias, ou seja, quanto maior o pedido feito, maior os custos para os manter estocado.

Segundo Padoveze (2012), existem dois tipos de estoques na indústria, sendo eles: os acabados e os em elaboração. Isso demonstra que a produção e compras são realizadas visando a venda futura.

Nas palavras de Wilker (2019), estoque são mercadorias contidas dentro de um espaço físico no qual são estocadas e industrializadas, sendo denominadas de produtos acabados. Para assim, atender consequentemente consumidores e outras empresas que estão sempre à procura de mercadorias diversas.

Como aponta Paloeschi (2014), pensando em uma esfera empresarial, a manutenção de um estoque traz ganhos, como beneficiar-se de espaços físicos, para melhor gestão do espaço e desempenhar um bom trabalho dentro da empresa, uma vez que quando utilizados corretamente, há fluidez e agilidade para atendimentos de pedidos. 
Segundo Grant (2013), atualmente é necessário otimizar o tempo para melhor atender aos clientes internos e externos em qualquer segmento empresarial. Portanto, é imprescindível gerenciar melhor as equipes, delegar de forma ordenada as funções para cada colaborador e estar de comum acordo com as novas tecnologias que acompanham o mercado.

\subsubsection{GESTÃO DE ESTOQUES}

Segundo Viera (2009, p. 21), há três fases importantes na cadeia de suprimentos que estão interligadas diretamente aos resultados dentro da empresa, podendo mudar o rumo da empresa em relação a fins financeiros.

Com o propósito de assegurar a competitividade e a sobrevivência no novo contexto econômico, a empresa deve ser gerenciada com base em sua estratégia. Se faz necessário para o controle e planejamento que a indústria determine onde quer chegar a longo prazo, a visão de futuro, os valores que motivam a ação empresarial e os objetivos estratégicos em relação aos concorrentes. Dessa forma, uma empresa formula suas estratégias buscando alocar eficazmente seus recursos com base nas suas competências e postura ambiental. (BRUNI e GOMES, 2010, p. 221).

Para Chin (2010), as organizações exigem estratégias proativas e eficazes, baseadas nas necessidades dos clientes. Sendo assim, para melhor compreensão destas é primordial verificar minuciosamente como está a organização neste momento.

$\mathrm{Na}$ visão de Ching (2010, p. 19), as organizações/indústrias demandam um rigoroso desenvolvimento dos estoques, aliados a vários objetivos, planos e planejamentos que devem ser seguidos dia após dia por cada colaborador, visando a melhoria contínua no setor de estoque.

Para Grant (2013), a gestão de estoque tem enfoque para a organização e alocação das mercadorias. Portanto, é necessário tomar a decisão correta, para definir corretamente o local das mercadorias, a fim de que não haja nenhum tipo de problema quanto às movimentações de cada item. 


\subsubsection{REFLEXO DO CONTROLE DE ESTOQUE PARA O PROCESSO DECISÓRIO}

De acordo com Fleuriet (2015, p. 23), a empresa deve ter maturidade estática, pois o estoque gera recursos financeiros que serão utilizados para o pagamento de outras contas, como: bens, serviços e fornecedores.

Para Silva (2020), os reflexos dos custos estarão alinhados em saber em qual data comprar, qual quantidade estocar para atender demandas de produção industrial e de outros ramos empresariais.

Segundo Grant (2013), devemos assumir riscos e aprender a evitar que ocorram novamente. Nos últimos anos, surgiram vários tipos de problemas ligados à cadeia de suprimentos que afetam diretamente o lado financeiro de uma empresa. Estes, se prevenidos antes que aconteçam, acarretarão benefícios a indústria.

De acordo com Gonçalves (2013), para se tornar referência em um mundo competitivo, é necessário entregar produtos e serviços de forma rápida com qualidade e a máxima eficiência para os clientes.

Seguindo o contexto de Bezos (2014), é importante salientar a necessidade de estudos constantes e o emprego de novas tecnologias na cadeia de suprimentos dentro de uma empresa.

\subsection{MÉTODOS DE CONTROLE DE ESTOQUES}

ludicibus et al. (2016, p. 101) afirma que "os estoques representam um dos ativos mais importantes do capital circulante e da posição financeira da maioria das companhias industriais e comerciais", portanto, o estoque claramente pode ser apontado como bens produzidos ou adquiridos de terceiros pela empresa, possuindo um fim correspondente ao uso pretendido. 
De acordo com Gonçalves (2016), é válido salientar que o uso de vários métodos para análise e controle dos estoques deve considerar as diferentes formas de calcular o preço de cada produto. Já para Dias (2015), existem três métodos para controlar os estoques permanentemente: PEPS, UEPS e custo médio, nos quais o objetivo é controlar a quantidade de material em estoque, tanto físico, quanto financeiro, informando todos os seus valores.

\subsubsection{PEPS}

Considera-se que, neste método, o Primeiro que Entra é o Primeiro que Sai (Peps). Portanto, os estoques serão avaliados pelas últimas compras, dessa forma, o saldo do estoque ficará valorizado pelos preços de custos mais atuais. Assim sendo, de maneira simplificada, para execução, necessitam do controle de saldos do material de acordo com seus preços de custo e variáveis de cada aquisição.

No caso de uma elevação dos preços por conta da inflação, os custos das mercadorias vendidas, por exemplo, serão feitos pelos preços menores, tendo em vista que estas são as mercadorias mais antigas. Portanto, os resultados das empresas poderão ser superestimados.

Para Dias (2014), o seu custo real será aplicado conforme ocorre à valorização dos estoques, devendo ser avaliado quando o giro desse mudar rapidamente, levando em consideração as variações que serão agregadas ao preço final do produto, considerando que o material seja mantido por um longo período.

Gonçalves (2016) informa que este método considera a ordem de entradas e saídas dos produtos de acordo com os seus respectivos preços.

Este método é muito utilizado no estoque de produtos perecíveis, pois assim, as mercadorias mais antigas saem primeiro, evitando o desperdício do produto caso vença.

Exemplo:

RC: 100626

Disponível em:

https://www.nucleodoconhecimento.com.br/contabilidade/controladoria-aplicada 
Uma empresa possui o Estoque Inicial, em 01/08/2021, composto por 40 unidades, adquiridas por $R \$ 2.000$, cada uma, totalizando $R \$ 80.000$. Dentre de um mês ocorreram as seguintes transações:

05/08 - Compra de 10 unidades por $\$ 2.200$, cada uma.

10/08 - Requisição de 8 unidades.

15/08 - Requisição de 35 unidades.

20/08 - Devolução de 2 unidades da requisição de 15/08.

25/08 - Compra de 20 unidades por $\mathrm{R} \$ 2.400$, cada uma.

30/08 - Devolução de 4 unidades da compra anterior.

Tabela 01 - Movimento de estoques e cálculo pelo método PEPS.

\begin{tabular}{|c|c|c|c|c|c|c|c|c|c|}
\hline \multirow[t]{2}{*}{ DIA } & \multicolumn{3}{|c|}{ ENTRADA } & \multicolumn{3}{|l|}{ SAÍDA } & \multicolumn{3}{|l|}{ SALDO } \\
\hline & $\begin{array}{l}\text { QUAN } \\
\text { T. }\end{array}$ & $\begin{array}{l}\text { VALO } \\
\text { R } \\
\text { UNIT. }\end{array}$ & $\begin{array}{l}\text { TOT } \\
\text { AL }\end{array}$ & $\begin{array}{l}\text { QUAN } \\
\text { T. }\end{array}$ & $\begin{array}{l}\text { VALO } \\
\text { R } \\
\text { UNIT. }\end{array}$ & $\begin{array}{l}\text { TOT } \\
\text { AL }\end{array}$ & $\begin{array}{l}\text { QUAN } \\
\text { T. }\end{array}$ & $\begin{array}{l}\text { VALO } \\
\text { R } \\
\text { UNIT. }\end{array}$ & $\begin{array}{l}\text { TOTA } \\
\text { L }\end{array}$ \\
\hline $01 / 08$ & & & & & & & 40 & 2.000 & $\begin{array}{l}80.00 \\
0\end{array}$ \\
\hline $05 / 08$ & 10 & 2.200 & $\begin{array}{l}22.00 \\
0\end{array}$ & & & & $\begin{array}{l}40 \\
10 \\
50\end{array}$ & $\begin{array}{l}2.000 \\
2.200\end{array}$ & $\begin{array}{l}80.00 \\
0 \\
22.00 \\
0 \\
102.0 \\
00\end{array}$ \\
\hline $10 / 08$ & & & & 8 & 2.000 & $\begin{array}{l}16.00 \\
0\end{array}$ & 32 & 2.000 & 64.00 \\
\hline
\end{tabular}

RC: 100626

Disponível em:

https://www.nucleodoconhecimento.com.br/contabilidade/controladoria-aplicada 


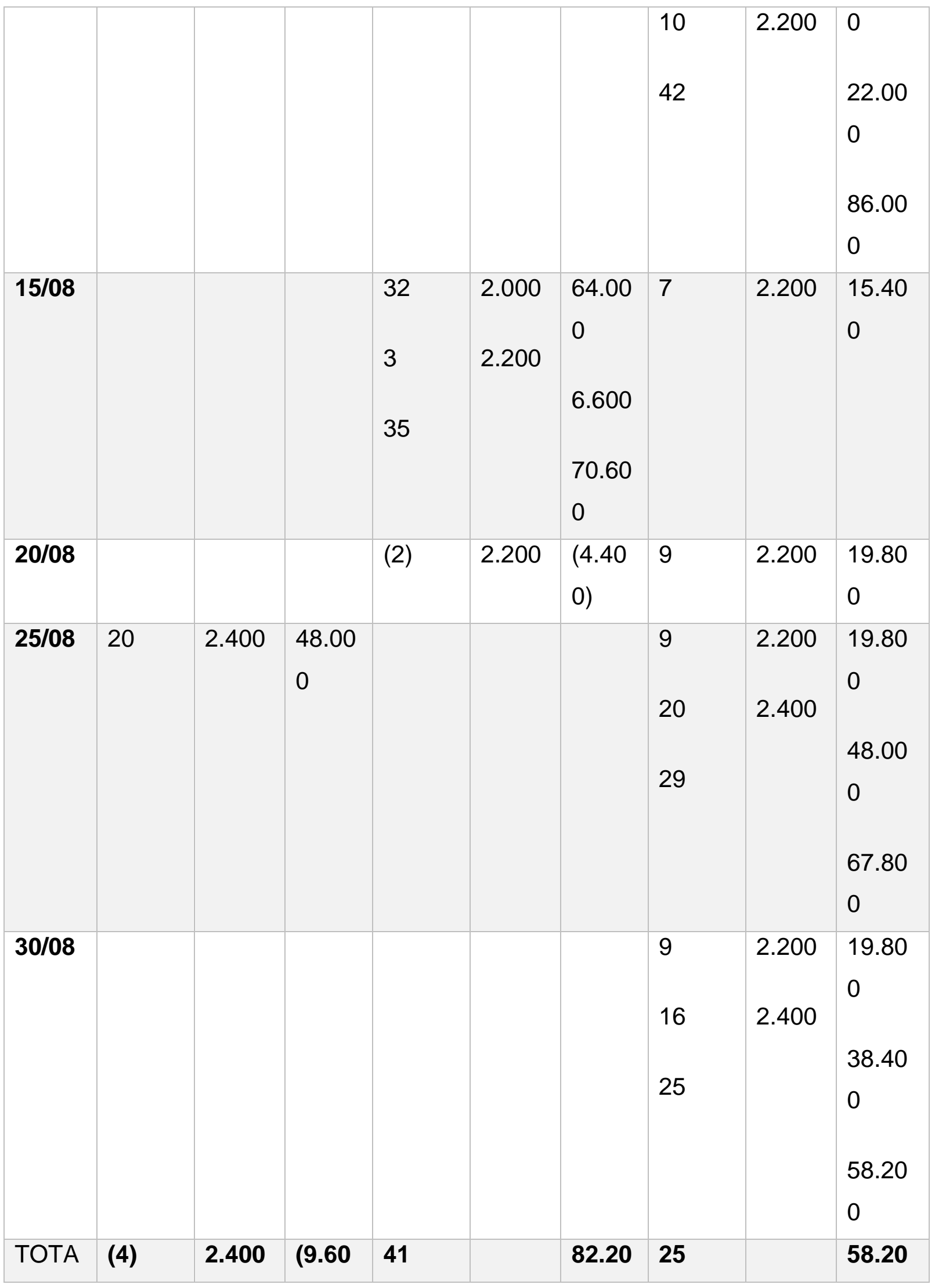

RC: 100626

Disponível em:

https://www.nucleodoconhecimento.com.br/contabilidade/controladoria-aplicada 
Fonte: Berbel (2003).

Dessa maneira concluímos que o custo total dos materiais requisitados será de $\mathrm{R} \$$ $82.000,00$ e o valor em estoque de $\mathrm{R} \$ 58.200,00$.

Esse método é recomendado pela Receita Federal, sendo exigido que o Custo das Mercadorias Vendidas (CMV) seja deduzido a partir das Demonstração do Resultado dos Exercícios (DRE).

\subsubsection{UEPS}

Segundo Santos et al. (2015), o estoque deverá ser avaliado por valores mais antigos. Dependendo do fluxo de vendas, os estoques mais antigos, podem se perpetuar na empresa, podendo causar grandes distorções de avaliação e de apuração dos resultados, quando esses forem vendidos. Já para Gonçalves (2016), as saídas serão efetuadas de acordo com as quantidades de cada entrada, ou seja, descontando as quantidades conforme o histórico das entradas.

Para Martins; Alt (2009), por ser um procedimento bastante utilizado pela economia inflacionária, este método se baseia na ordem cronológica das entradas e saídas. Dias (2015) considera que o primeiro a sair deverá ser o último a entrar no estoque, dessa maneira, há uma valorização do saldo conforme os últimos preços, ou seja, nesse caso, facilitará a contabilização dos produtos para definição de preços de vendas e refletirá em custos mais próximos da realidade de mercado.

\section{Exemplo:}

Tabela 02 - Movimento de estoques e cálculo pelo método UEPS.

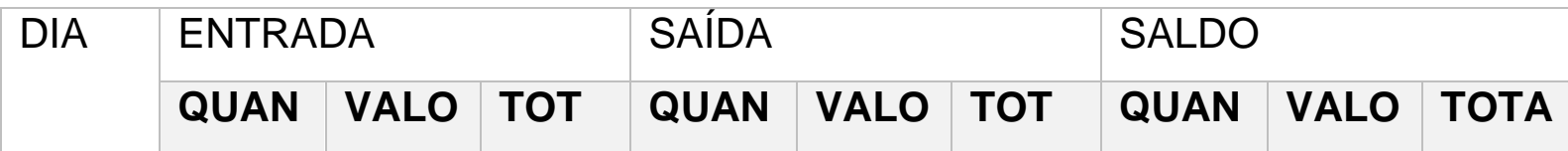




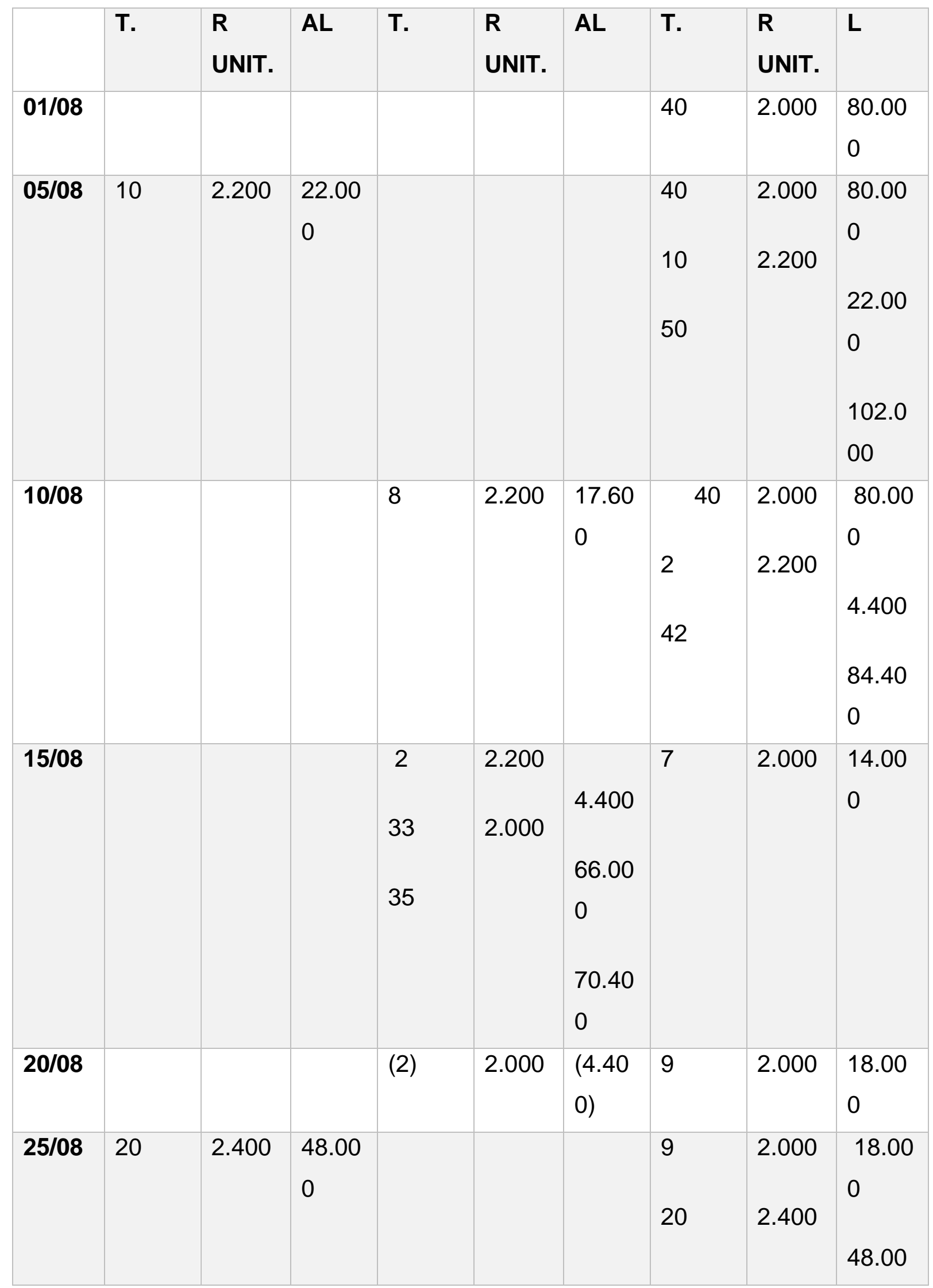

RC: 100626

Disponível em:

https://www.nucleodoconhecimento.com.br/contabilidade/controladoria-aplicada 


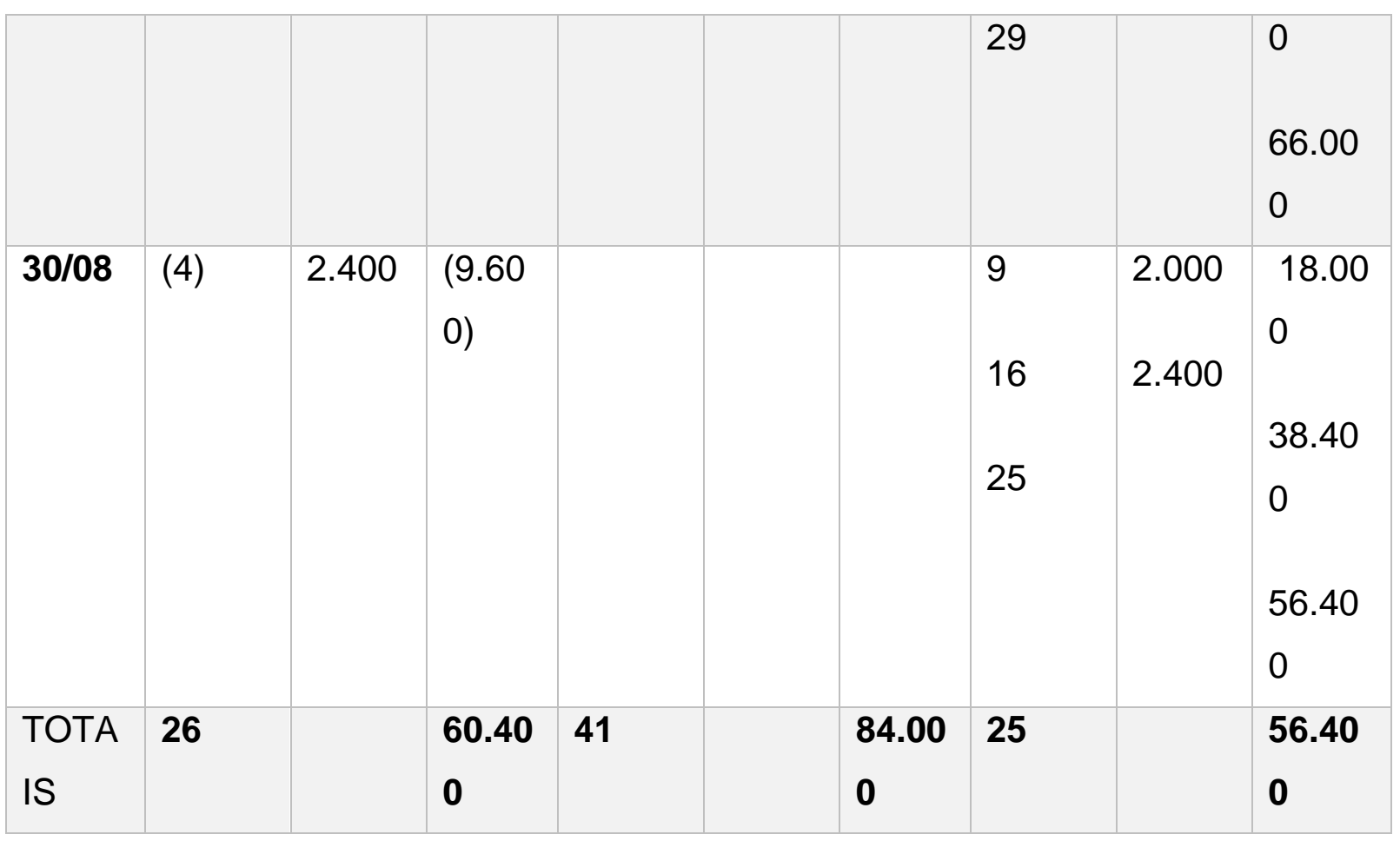

Fonte: Berbel (2003).

Dessa forma, conforme exposto no exemplo acima, o custo dos materiais requisitados no período será de $R \$ 84.000$, e o valor do estoque, $R \$ 56.400$.

Portanto, o procedimento das entradas são os mesmos, porém, as saídas, ocorrem de acordo com os valores das últimas entradas, isto ocorre até que o saldo da primeira aquisição acabe e, assim, o estoque da próxima aquisição comece a ser utilizado.

Vale ressaltar, conforme Almeida (2010), que, nesse método, as quantidades que permanecem em estoque são reconhecidas pelos seus primeiros custos unitários, já as saídas de estoque serão pelos últimos custos unitários. Dessa maneira, este método não é manuseado pela legislação Brasileira por existir a probabilidade de haver aumento da inflação e afetar os estoques subavaliando-os, diminuindo, assim, a lucratividade por parte da empresa. 


\subsubsection{CUSTO MÉDIO}

O método mais usado no Brasil é o do Custo Médio, pois o processo é simples e age como um moderador de preços, ou seja, este método é mais justo em nível de pagamentos de impostos e é aceito pelo Fisco.

Martins; Alt (2009) determinam que o processo de cancelamento de um item de estoque geralmente é concluído pela quantidade da própria ordem de produção e o valor do saldo final que é dado pelo preço médio do produto.

Com isso em mente, a indústria, em sua grande maioria, utiliza o custo médio para realizar a entrada de suas mercadorias em seu sistema, elevando, assim, na grande maioria das vezes, o seu preço de venda, por se tratar de uma média de todo o estoque existente. Almeida (2010, p. 197) afirma que "por este método as quantidades que ficam em estoque e as que saem são valorizadas pelo custo unitário médio de aquisição ou de fabricação".

Exemplo:

Considerando os mesmos dados fornecidos nos exemplos dos métodos anteriores.

Tabela 03 - Movimento de estoques e cálculo pelo método Custo Médio

\begin{tabular}{|c|c|c|c|c|c|c|c|c|c|}
\hline \multirow[t]{2}{*}{ DIA } & \multicolumn{3}{|c|}{ ENTRADA } & \multicolumn{3}{|l|}{ SAIIDA } & \multicolumn{3}{|c|}{ SALDO } \\
\hline & $\begin{array}{l}\text { QUAN } \\
\text { T. }\end{array}$ & $\begin{array}{l}\text { VALO } \\
\text { R } \\
\text { UNIT. }\end{array}$ & $\begin{array}{l}\text { TOT } \\
\text { AL }\end{array}$ & $\begin{array}{l}\text { QUAN } \\
\text { T. }\end{array}$ & $\begin{array}{l}\text { VALO } \\
\text { R } \\
\text { UNIT. }\end{array}$ & $\begin{array}{l}\text { TOT } \\
\text { AL }\end{array}$ & $\begin{array}{l}\text { QUAN } \\
\text { T. }\end{array}$ & $\begin{array}{l}\text { VALO } \\
\text { R } \\
\text { UNIT. }\end{array}$ & $\begin{array}{l}\text { TOTA } \\
\text { L }\end{array}$ \\
\hline $01 / 08$ & & & & & & & 40 & 2.000 & $\begin{array}{l}80.00 \\
0\end{array}$ \\
\hline $05 / 08$ & 10 & 2.200 & $\begin{array}{l}22.00 \\
0\end{array}$ & & & & 50 & 2.040 & $\begin{array}{l}102.0 \\
00\end{array}$ \\
\hline $10 / 08$ & & & & 8 & 2.040 & $\begin{array}{l}16.32 \\
0\end{array}$ & 42 & 2.040 & $\begin{array}{l}85.68 \\
0\end{array}$ \\
\hline
\end{tabular}

RC: 100626

Disponível em:

https://www.nucleodoconhecimento.com.br/contabilidade/controladoria-aplicada 


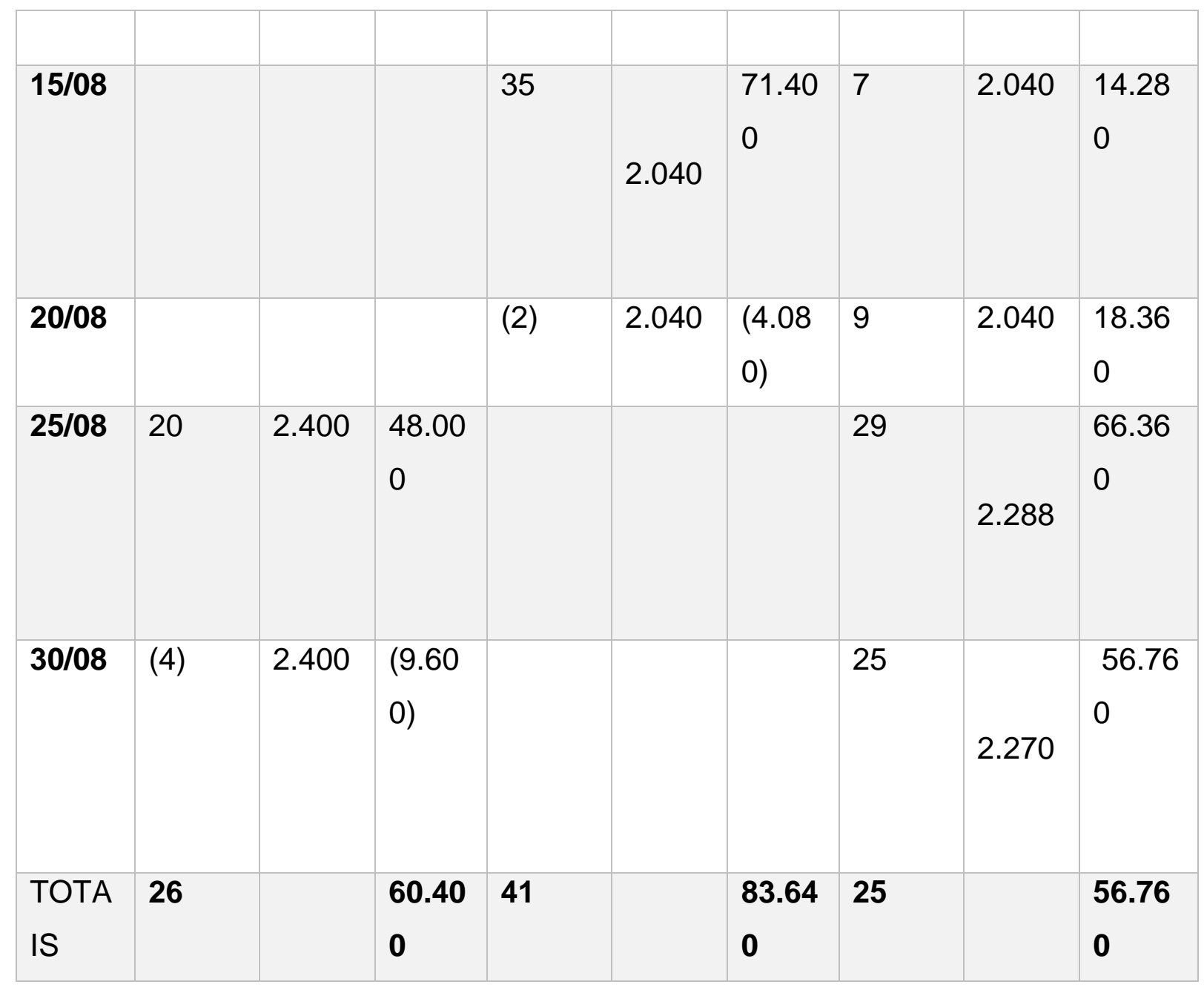

Fonte: Berbel (2003).

$05 / 11: 102.000 / 50=2.040$

$25 / 11: 66.360 / 29=2.288$

De acordo com a tabela acima, o custo dos materiais requisitados no período será de $\mathrm{R} \$ 83.640$ e o valor do estoque $\mathrm{R} \$ 56.760$.

Portanto, em cada movimentação de compra ou fornecimento, ou seja, entrada ou saída, é necessário atualizar a quantidade existente, recalculando o valor residual e atualizando o preço médio.

Comparando-se os resultados obtidos para os critérios apresentados, temos:

RC: 100626

Disponível em:

https://www.nucleodoconhecimento.com.br/contabilidade/controladoria-aplicada 
Quadro 01 - Comparativo dos métodos de controle de estoques

\begin{tabular}{|c|c|c|}
\hline Peps & Ueps & $\begin{array}{l}\text { Média Ponderada } \\
\text { Móvel }\end{array}$ \\
\hline$\left(^{*}\right)$ CMR 82.200 & CMR 84.000 & CMR 83.640 \\
\hline $\begin{array}{l}\text { Estoque } \quad \text { Final } \\
58.200\end{array}$ & Estoque Final 56.400 & Estoque Final 56.760 \\
\hline
\end{tabular}

Fonte: própria (2021)

$\left.{ }^{*}\right)$ Custo dos materiais requisitados

Notasse que a adoção de qualquer dos um dos critérios tem interferência direta no Custo de Produção e no valor do estoque final de materiais.

\subsection{ATUAÇÃO DA CONTROLADORIA NA GESTÃO DE ESTOQUES INDUSTRIAIS}

Brezan e Silva (2012), pontuam que o ambiente organizacional passou por diversas transformações ao longo do tempo, produzindo novos desafios às empresas. Para permanecer no mercado empresarial, é fundamental a busca pelo domínio das informações para o direcionamento no processo decisório, apoiando os gestores no contexto das tomadas de decisões, gerenciando com cautela os estoques, evitando o desperdício, a falta ou o atraso na produção.

Ressalta-se que o estoque traz muitos benefícios, mas o alto custo de investimento nesses ativos se tornou um grande problema para as indústrias. Dias (2010) afirma que 0 investimento em estoque é imprescindível para o processo de produção, tornando evidente que a insuficiência afetará a velocidade e limitará a transformação da matéria prima em produto acabado. 
Para Syntetos; Keyes; Babai (2009), as organizações que estocam peças de reposição geralmente classificam esses itens de acordo com critérios aos quais estão relacionados, reconhecendo a existência de diversos níveis diferentes para cada categoria.

Segundo Coelho; Lunkes e Machado (2012), entende-se que implantar um departamento responsável pela análise e manutenção do processo de operações do setor de estoque, aliado às informações financeiras e contábeis, podem auxiliar a alta administração no processo de tomada de decisão, adotando uma postura linear. Obviamente, o direito de controle deve ser visto como um auxílio à outras áreas, dando suporte aos gestores

Seguindo esse contexto, Flesch (2010), ressalta-se que, no Brasil, o setor industrial é conhecido por seu potencial, o que requer o controle de seus ativos. Contudo, constata-se que nesse quadro se torna fundamental o controle de estoque industrial, pois fornece suporte e informação à administração para que se estabeleçam procedimentos e contabilizem provisão para perdas com itens sem movimento e com movimentação lenta.

Para Assaf Neto (2009), os próprios bens ou produtos que a empresa produz tem a finalidade de venda. Desta forma, este processo está inter-relacionado com o departamento de controladoria, que por sua vez, tenta entender os parâmetros do sistema que afetam diretamente a definição do estoque de segurança, tamanho mínimo do lote e outros aspectos para garantir que não haja inventário em excesso.

Segundo Brenzan, e Silva (2012), o Controller é responsável pela implementação e atualização de um sistema integrado dentro das industriais, devendo se preocupar com a eficiência de todos os departamentos da empresa, principalmente com a situação financeira, e assim, prover informações precisas para os gestores, revelar os pontos críticos que demandam uma atenção de maior análise por parte dos dirigentes de cada área, indicando com precisão as projeções futuras. 
Nunes (2014) acentua que esse contexto está voltado para a estruturação do sistema de coleta de dados, sendo uma função diretamente subordinada à presidência e, para funcionar de forma apropriada, necessita-se de departamentos contábeis para gerar análises e relatórios de ganhos e perdas.

Nesse sentido, é comum a comparação dos setores de uma empresa com as partes que integram o corpo humano (TADEU; ROCHA, 2010). Assim sendo: "o coração da empresa seria como a área de produção; o pulmão, a área de estoques; e o cérebro, a sua área de planejamento", assim, como no corpo humano, cada membro tem sua função vital, os gestores da organização, precisam ter em mente que todos os setores têm sua importância (TADEU; ROCHA, 2010, p. 6).

A questão da gestão de estoque é de relevância para qualquer organização, pois "a armazenagem de mercadorias prevendo seu uso futuro exige investimento por parte das empresas" (BALLOU, 2012, p. 204). Por isso, há sempre a necessidade de gestão eficaz dos processos administrativos, compras e armazenagem, para que isso não acarrete custos ou passivos para a indústria.

Sendo assim, "o controle de estoques exerce influência muito grande na rentabilidade da empresa" (BALLOU, 2012, p. 208).

\subsubsection{GESTÃO E MELHORIAS}

Os setores administrativos, determinados a obter eficácia em sua gestão, tem buscado maior interação com o setor operacional, por meio de tecnologias automatizadas para o fluxo e rotatividade de produto, visando $99,99 \%$ de acerto no estoque empresarial.

É preciso a conscientização de que o planejamento estratégico é um processo de observação, análise e projeção do que será feito, visando orientar os gestores com base nos levantamentos de diversas variáveis e elaborados orçamentos. Para Catelli et al. (2010), se torna pré-requisito para garantir o acatamento dos objetivos e a 
perenidade da empresa. Ele começa definindo cenários, em seguida, identificando oportunidades e ameaças e, finalmente, formulando diretrizes estratégicas.

Já para Rego et al. (2011), outra maneira de reduzir o a elevação de estoque de peças de reposição, é revisar estritamente se cada item ativo precisa ser retido, considerando o modelo desenvolvido sob a premissa de que os dados do estoque devem sempre ser reavaliados.

Averiguou-se ser primordial, para o crescimento da indústria, a implementação de um sistema interno, com o principal objetivo de fornecer informações oportunas e relevantes aos gestores para que estes possam melhorar todos os dados a fim de contribuir com o crescimento da empresa.

Desta forma, Carneiro et al. (2016) acentua-se que desde que bem estruturada, a controladoria, é a chave para nortear o processo a ser traçado para alcançar seus objetivos sociais, missão, visão e valores.

Entende-se com esse estudo que o desempenho e a eficácia dos estoques podem ser aumentados substancialmente através da integração da informação (previsões, pedidos, planos) para toda a cadeia de distribuição e empresa em geral.

Para Tadeu (2010), em uma indústria sem planejamento, o estoque fica sem movimentação, ocorrendo a elevação dos custos, o aumento dos preços e redução da produção.

Segundo Campos (2009), para que a indústria obtenha uma vantagem competitiva em sua gestão interna, deve-se otimizas e coordenar as atividades. Nesse sentido, é primordial a utilização de ferramentas que forneçam resultados a fim de gerenciar corretamente o estoque da empresa. 


\subsubsection{SISTEMA INTEGRADO DE INFORMAÇÕES}

Nos tempos atuais, com a evolução econômica e a implantação desses sistemas, as indústrias estão exigindo que seus profissionais tenham em seu perfil não só experiência nesta área, mas também, que estejam aptos a trabalhar com ferramentas tecnológicas, a fim de decidir de forma eficaz os rumos da produção, solucionando os problemas que poderão afetar o bom andamento. Filatro e Loureiro (2020), afirmam que cada vez mais softwares customizados são vendidos, pois são utilizados em nuvens sem precisar fazer a instalação.

O controle digital dos produtos acessíveis e requeridos apresenta inúmeros benefícios, incluindo a menor intervenção humana no fluxo da informação, permitindo uma menor margem de erro e a simultaneidade da informação.

Para com Vieira (2009), o sistema ERP (Planejamento Integrado de Recursos) interliga os setores da empresa, possibilitando a verificação das áreas e informações contábeis extraídas, configurando transparência e a transmissão de informações corretas. Atualmente, dependemos de muitos desses sistemas de informações, pois como o mundo vem mudando repentinamente, é necessário ter agilidade no repasse de informações para que os empresários tomem as devidas decisões.

Segundo Chambers (2009), para enfrentar os conjuntos particulares de condições de controle de estoque, recomenda-se que as empresas procurem investir em um sistema de processamento de informações que se adequem a sua necessidade.

Diante disso, o Controller, tem como função integralizar e atualizar as informações, apoiando no poder decisório diante das informações colhidas.

De acordo com Oliveira; Perez Jr e Silva (2010), o Controller é como o executor primordial da controladoria. Dessa maneira, é evidente que este profissional não só controla, mas também é responsável por definir estratégias para atingir os objetivos da indústria. 
Segundo Lunkes e Schnorrenberger (2009), uma das ferramentas aplicadas no planejamento e execução é o orçamento, por promover o diálogo e a disciplina dos fatos e setores. Sendo assim, compreende-se que este processo tem inúmeras finalidades que podem servir de parâmetros para planos de avaliação, permitindo apurar os resultados com o escopo de responsabilidade. Neste caso, o sistema contábil, tem um papel de controle, e é presente em todo o ciclo administrativo, podendo ser definido em um sentido amplo de perspectiva metódica e formal executando as responsabilidades de planejamento, execução e controle.

Para Bruni e Gomes (2010), o sistema ERP (Planejamento Integrado de Recursos) é importante para as empresas no quesito de repassar informações de forma rápida e eficaz, proporcionando aos gestores informações em curto tempo e com exatidão, de acordo com a parametrização da empresa. Esses sistemas, possuem vários modelos para atender as empresas e dar para os gestores informações contundentes a fim de tomar a decisão certa.

Abaixo há a representação de alguns modelos mais atuais utilizados em indústrias brasileiras. Os dados indicam que o TOTVS é um dos sistemas mais usados atualmente e em alta ascensão. Este é completo e com informações rápidas para tomada de decisão em uma empresa. Em segundo está o SAP, que possui diversos relatórios gerenciais. 
Figura 01 - Sistemas utilizados no Brasil pelas empresas industriais

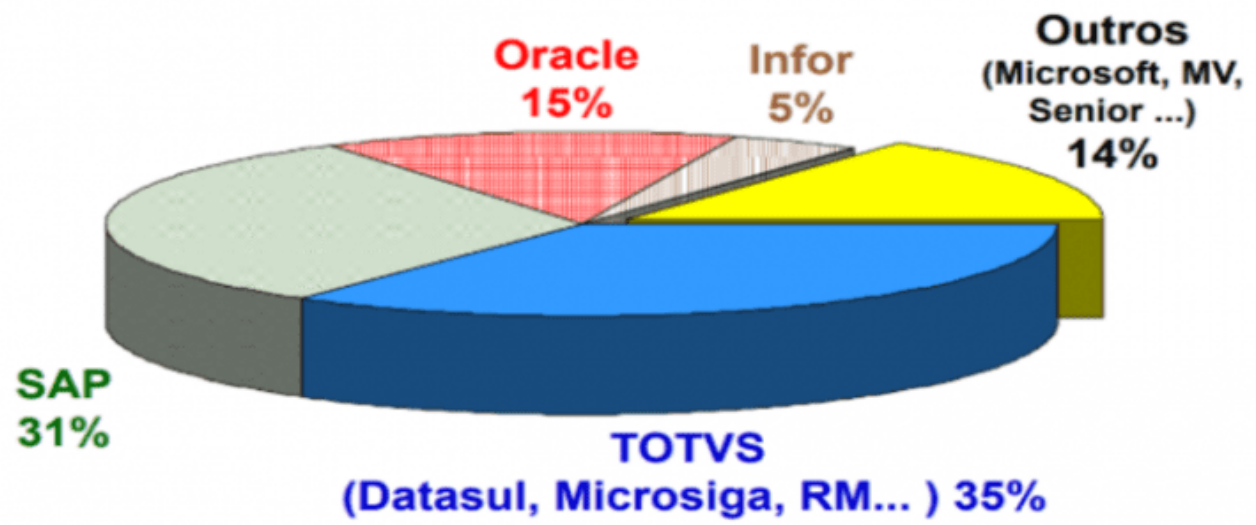

Fonte: 29aㅗ Pesquisa anual de TI, 2018.

\section{MATERIAIS E MÉTODOS}

A estratégia de pesquisa adotada foi a pesquisa bibliográfica, qualitativa de natureza exploratória. Foram realizadas buscas em obras já publicadas, relevantes para conhecer e analisar o tema da pesquisa.

Para Andrade (2010, p. 25):

A pesquisa bibliográfica é habilidade fundamental nos cursos de graduação, uma vez que constitui o primeiro passo para todas as atividades acadêmicas. Uma pesquisa de laboratório ou de campo implica, necessariamente, a pesquisa bibliográfica preliminar. Seminários, painéis, debates, resumos críticos, monográficas não dispensam a pesquisa bibliográfica. Ela é obrigatória nas pesquisas exploratórias, na delimitação do tema de um trabalho ou pesquisa, no desenvolvimento do assunto, nas citações, na apresentação das conclusões. Portanto, se é verdade que nem todos os alunos realizaram pesquisas de laboratório ou de campo, não é menos verdadeiro que todos, sem exceção, para elaborar os diversos trabalhos solicitados, deverão empreender pesquisas bibliográficas (ANDRADE, 2010, p. 25).

RC: 100626

Disponível em:

https://www.nucleodoconhecimento.com.br/contabilidade/controladoria-aplicada 


\subsection{PROCEDIMENTOS METODOLÓGICOS}

O estudo pode ser qualificado como qualitativo de natureza exploratória, baseado em pesquisa bibliográfica. Conforme afirma Ludwig (2009), esse método é muito utilizado na área acadêmica, abordando a análise das informações contidas em livros e artigos publicados por estudiosos e especialistas, permitindo por parte do pesquisador a interpretação e desenvolvimento em relação ao assunto pesquisado.

\subsubsection{QUANTO À NATUREZA}

Quanto à natureza, foi abordado a análise das informações de dados secundários disponibilizados em teses, dissertações, artigos e livros. Como afirmam Prodanov e Freitas (2013), a pesquisa adotará a interpretação do subjetivo do objeto analisado. Constata-se que o objetivo primordial é proporcionar maior familiaridade com o problema, com vistas a torná-lo mais explícito, dessa maneira, fica claro que o levantamento bibliográfico é fundamental para análise dos resultados.

Deste modo, para Flick (2009), o propósito não é mensurar quantidades ou resultados, mas sim compreender o comportamento ou desenvolvimento do alvo da pesquisa.

\subsubsection{QUANTO AOS FINS}

Para alcançar o objetivo da pesquisa, realizou-se um estudo de natureza exploratória por se tratar de uma área na qual há pouco conhecimento, sendo desenvolvida por meio do levantamento documental e bibliográfico. Este método auxiliou na análise do processo em averiguação para constatar o problema com vista a torná-lo mais explícito ou a construir hipóteses e soluções. Casarin e Casarin (2012) demonstram que toda pesquisa é realizada visando atingir um objeto, dessa maneira, ocorre que a pesquisa exploratória busca levantar informações sobre um determinado objeto, delimitando, assim, um campo de trabalho e mapeando as condições de manifestação desse objeto. 
Para Marconi e Lakatos (2010), para os devidos fins, o estudo tem como principal objetivo buscar intervir quanto à resolução de problemas, colhendo informações documentais e bibliográficas de caráter exploratório.

\subsubsection{QUANTO AOS MEIOS}

O intuito desse trabalho é evidenciar a importância da controladoria aplicada na gestão de estoque de uma indústria, por meio de seus conceitos no setor, buscando com estas informações apresentar as ferramentas de controle, suas classificações e seus critérios. Uma vez que esta pode ser definida como uma importante ferramenta de gestão, de modo que, através dos relatórios elaborados, os gestores recebam auxílio no controle e planejamento da organização.

Desse modo, pode-se asseverar que o estudo deste trabalho é caracterizado como bibliográfico, uma vez que tem como fonte de dados livros e artigos científicos. Para Gil (2010) constata-se que, neste tipo de pesquisa, é realizado, inicialmente, um levantamento bibliográfico e documental, que servirá de base para a organização e elaboração dos tópicos da fundamentação teórica, assim como, para construir hipóteses e soluções.

Kôche (2015) por sua vez pontua que a pesquisa busca levantar informações sobre um determinado objeto, utilizando o conhecimento disponível a partir de teorias publicadas em dissertações, artigos e livros, com o intuito de proporcionar análises e interpretações por parte do pesquisador.

\section{CONSIDERAÇÕES FINAIS}

Em vista dos argumentos apresentados neste artigo, é notório que o papel da controladoria como gestão em uma determinada indústria tem caráter decisório.

Dessa forma, a controladoria repassa às partes interessadas da empresa, informações concisas e claras para tomada de decisão de qualquer etapa interna e externa que envolve uma relação empresarial.

RC: 100626

Disponível em:

https://www.nucleodoconhecimento.com.br/contabilidade/controladoria-aplicada 
Em resposta à pergunta problema: de que maneira a controladoria direcionada à gestão de estoque pode auxiliar na continuidade do negócio? Concluímos que a controladoria tem como função trazer alternativas e melhorias eficientes para o processo decisório, principalmente na gestão de estoque, onde o profissional de controladoria é de suma importância. Avaliando os conceitos propostos, pode-se entender que a controladoria aplicada na gestão de estoque busca garantir, também, a eficiência da indústria por meio de informações qualitativas que contribuam para otimização dos resultados da organização.

Bruni e Gomes (2010), afirma que o sistema ERP (Planejamento Integrado de Recursos) é importante para as indústrias no quesito de repassar informações de forma rápida e eficaz, auxiliando na tomada de decisões.

Concluímos, durante a pesquisa, que nos aspectos indústrias, sem um modelo de gestão aliado a controladoria é difícil lidar com os processos de gestão de estoque, uma vez que o papel decisório é de suma importância para crescimento e desenvolvimento do negócio. Por fim esperamos que esta pesquisa possa servir de estudo para os acadêmicos e outros interessados no assunto abordado.

\section{REFERÊNCIAS}

ABREU, A.; CARVAlHO, J. V.; ROCHA, Á. Novos desafios dos Sistemas de Informação no contexto atual das organizações. RISTI, 30, 9-21, 2018.

\section{ALEMÃO, M. M.; GONÇALVES, M. A.; DRUMOND, H. A. Estudo da utilização da informação de custos como ferramenta de gestão em organização pública: o estudo do SIGH-Custos. Perspectivas em Gestão \& Conhecimento, v. 3, n. 1, p. 210-226, 2013.}

ASSAF NETO, A. Administração do Capital de Giro. 4aㅗ ed. Editora Atlas, São Paulo, 2009. 
BALLOU, R. H. Logística empresarial: transportes, administração de materiais e distribuição física. 1 ed. trad. Hugo T. Y. Yoshizaki. 26 reimp. São Paulo: Atlas, 2012.

BERBEL, J. D. S. Introdução à Contabilidade e Análise de Custos. São Paulo, 2003.

BRENZAN, R. e SILVA, T. A. M. O papel da controladoria no processo de tomada de decisão nas organizações. Revista de Administração da FATEA, 5(5), 125-146, 2012.

BRUNI, A. L.; GOMES, S. M. da S. Controladoria: conceitos, ferramentas e desafios. Salvador: EDUFBA, 2010.

CASARIN, H. de C. S.; CASARIN, S. J. Pesquisa Científica da Teoria à Prática. Curitiba: Editora Intersaberes; 2012

CATELLI, A. Controladoria: uma abordagem da gestão econômica. GECON. $2^{a}$ edição. São Paulo: Atlas, 2010.

CHING, H. Y. Gestão de estoques na cadeia de logística integrada - Supply chain. 4. Ed. São Paulo: Atlas, 2010.

COELHO, E.; LUNKES, R. J.; MACHADO, A. O. A controladoria na hierarquia organizacional: um estudo nas maiores empresas do estado de Santa Catarina. UEM, Paraná, v. 31, n. 2, p. 33-46, maio/agosto 2012.

DIAS, M. A. P. Administração de materiais: uma abordagem logística. 5. Ed. São Paulo: Atlas, 2010.

DIAS, M. A. P. Administração de Materiais. 6ª edição. São Paulo. Editora Atlas, 2015. 
FLEURIET, M. O modelo dinâmico de gestão financeira. $1^{\underline{a}}$ ed. Editora: Alta Books, 2015

FLICK, U. Introdução à pesquisa qualitativa. Tradução Joice Elias Costa. 3.ed. Porto Alegre: Artemed, 2009

GONÇALVES, P. S. Administração de Materiais. 5. edição. Rio de Janeiro, Elsevier, 2016.

GRANT, D. B. Gestão de Logística e Cadeia de Suprimentos. Editora: Saraiva, Ano: 2013

HEICHSEN, L.; LUNKES, R. J.; ROSA, F. S. Adoção das funções da controladoria: um estudo em empresa do setor elétrico. Revista Inova Ação, 3(1), 01-18, 2014.

IUDÍCIBUS, S. de; MARION, J. C. Contabilidade Comercial. 10. ed. São Paulo: Atlas, 2016.

LAKATOS, E. M.; MARCONI, M. de A. Fundamentos de metodologia científica: Técnicas de pesquisa. 7 ed. - São Paulo: Atlas, 2010

LUNKES, R. J. e SCHNORRENBERGER, D. Controladoria: na coordenação dos sistemas de gestão. São Paulo: Atlas, 2009.

MARTINS, P. G; ALT, P. R. C. Administração de recursos materiais e recursos patrimoniais. 3. ed. rev. atual. São Paulo: Saraiva, 2009.

MÜLER, E. T. C.; BEUREN, I. M. Estrutura formal e práticas da controladoria em empresas familiares brasileiras. Gestão \& Regionalidade, v. 26, n. 76, art. 54, p. 105-120, 2010.

NUNES, A. A. B. Práticas de controladoria adotadas pelas organizações brasileiras. Revista de Administração e Contabilidade, 6(1), 42-56, 2014. 
OLIVEIRA, L. M.; PEREZ JR, J. H.; SILVA, C. A. dos S. Controladoria Estratégica. 5ª edição. São Paulo: Atlas 2009.

OLIVEIRA, L. M.; PEREZ JR, J. H.; SILVA, C. A. dos S. Controladoria Estratégica. 6ae edição. São Paulo: Atlas S.A, 2010.

PADOVEZE, C. L. Controladoria estratégica e operacional. São Paulo: Cengage Learning Edições, 2009.

PADOVEZE, C. L. Controladoria estratégica e operacional: conceitos, estrutura, aplicação. $3^{\underline{a}}$ ed. ver. e atual., São Paulo: Cengage Learning, 2012.

PAOLESCHI, B. Cadeia de Suprimento. 1. ed. São Paulo: Érica, 2014.

PRODANOV, C. C.; FREITAS, E. C. de. Metodologia do trabalho científico: métodos e técnicas da pesquisa e do trabalho acadêmico. 3. ed. Novo Hamburgo: Feevale, 2013.

RIBEIRO, O. M. Contabilidade Fundamental. 4. Ed. São Paulo. Saraiva. 2013.

SILVA, W. A importância da Contabilidade gerencial. Monografias Brasil escola, 2020. Disponível em: https://monografias.brasilescola.uol.com.br/administracaofinancas/aimportancia-contabilidade-gerencial-como-ferramenta-no-processotomada-decisao.htm. Acesso em: 16 Set. 2020

WARREN, C. S. et al. Fundamentos de Contabilidade: Aplicações. 22 ed. São Paulo: Cengage Learning, 2009.

SILVA, B. W. Gestão de Estoques: Planejamento, Execução e Controle. $2^{\mathrm{a}}$ edição, 2019.

Enviado: Outubro, 2021.

Aprovado: Novembro, 2021. 